\title{
Activation of the Notch-Nox4-reactive oxygen species signaling pathway induces cell death in high glucose-treated human retinal endothelial cells
}

\author{
WANZHEN JIAO ${ }^{1}$, JIAFU JI ${ }^{2}$, FENGJIAO LI ${ }^{1}$, JIANLIAN GUO ${ }^{3}$, YUANJIE ZHENG ${ }^{4-6}$, \\ SHANGBIN $\mathrm{LI}^{7}$ and WENWEN XU
}

\begin{abstract}
${ }^{1}$ Department of Ophthalmology, Shandong Provincial Hospital Affiliated to Shandong University, Jinan, Shandong 250021;
${ }^{2}$ Department of Anesthesiology, Affiliated Hospital of Shandong University of Traditional Chinese Medicine;

${ }^{3}$ Department of Ophthalmology, Jinan Eighth People's Hospital; ${ }^{4}$ School of Information Science and Engineering,

Shandong Normal University; ${ }^{5}$ Institute of Biomedical Sciences at Shandong Normal University;

${ }^{6} \mathrm{Key}$ Lab of Intelligent Computing and Information Security in Universities of Shandong, and

Shandong Provincial Key Laboratory for Distributed Computer Software Novel Technology, Jinan, Shandong 250014;

${ }^{7}$ Department of Healthcare, Shandong Provincial Hospital Affiliated to Shandong University,
\end{abstract}

Jinan, Shandong 250021, P.R. China

Received February 7, 2018; Accepted October 19, 2018

DOI: $10.3892 / \mathrm{mmr} .2018 .9637$

\begin{abstract}
Diabetic retinopathy (DR) occurs in almost all patients with diabetes and remains as one of the major causes of vision loss worldwide. Nevertheless, the molecular mechanisms underlying the pathogenesis of DR remain elusive. The present study aimed to investigate the role and association of Notch signaling and NADPH oxidase 4 (Nox4)-mediated oxidative stress in high glucose (HG)-treated retinal cells. Human retinal endothelial cells were cultured for various durations in RPMI-1640 medium containing $30 \mathrm{mM}$ glucose (HG) or $30 \mathrm{mM}$ mannitol (MN) as an osmotic control; apoptotic cell death and reactive oxygen species (ROS) levels were assessed, respectively. Alterations in the expression profiles of Nox and Notch proteins were evaluated using reverse transcription-quantitative polymerase chain reaction and
\end{abstract}

Correspondence to: Professor Wenwen Xu, Department of Ophthalmology, Shandong Provincial Hospital Affiliated to Shandong University, 324 Jingwu Road, Jinan, Shandong 250021, P.R. China

E-mail: xuwenwen3247@163.com

Abbreviations: DR, diabetic retinopathy; HG, high glucose; HRECs, human retinal endothelial cells; NICD, Notch intracellular domain; MN, mannitol; ROS, reactive oxygen species; siRNA, small interference RNA; DPI, diphenyleneiodonium; GSI, $\gamma$-secretase inhibitor IX; Nox, NADPH oxidase; RBPj, recombination signal-binding protein $\mathrm{J}$

Key words: diabetic retinopathy, high glucose, cell death, Notch, NADPH oxidase 4, reactive oxygen species, human retinal endothelial cells western blot analysis. Knockdown of Nox4 and recombination signal-binding protein $\mathrm{J}(\mathrm{RBPj})$ was generated by transfection with specific small interfering (siRNA). Persistent activation of Notch signaling was induced via the overexpression of Notch intracellular domain (NICD). In the present study, time-dependent increases in ROS production and cell death were detected in HG-treated cells. Depletion of ROS by diphenyleneiodonium decreased HG-induced cell death, and suppressed increases in caspase 3 activity and B-cell lymphoma 2-associated X protein levels. In HG-treated cells, Nox4 expression was upregulated at the mRNA and protein levels, and inhibition of Nox4 by GKT137831 or knockdown of expression by siRNA Nox4 significantly reduced ROS levels and cell death. In the presence of HG, Notch1 expression levels were elevated, and increased NICD abundance was detected in whole cell lysates and nuclear fractions. Additionally, HG-induced cell death was decreased by treatment with $\gamma$-secretase inhibitor (GSI), but increased via the overexpression of NICD. The application of GSI or knockdown of RBPj by siRNA RBPj prevented increases in Nox4 expression within HG-treated cells. The findings of the present study demonstrated that Nox4-mediated ROS serves an important role in HG-induced retinal cell damage, in which the activation of Notch signaling may be responsible for Nox4 upregulation. Therefore, inhibition of Notch signaling or Nox4 expression may be considered as potential therapeutic targets in patients with DR.

\section{Introduction}

Diabetic retinopathy (DR), a microvascular complication of diabetes mellitus, occurs in almost all patients with diabetes worldwide, leading to a severe consequence of blindness (1). A total of two types of DR have been identified: Non-proliferative $\mathrm{DR}$, which is characterized by microaneurysms and intraretinal 
hemorrhage, and proliferative DR, which has been identified by vitreous hemorrhage and neovascularization of the eye fundus and iris (1). Previous studies have demonstrated that chronic inflammatory and oxidative stress is associated with the development and progression of DR (2-4).

Elevated levels of reactive oxygen species (ROS) and reduced antioxidant enzyme activity have been observed in DR (5). The levels of methylglyoxal, a reactive $\alpha$-dicarbonyl compound of glucose metabolism, were elevated in patients with diabetes (6). In cultured bovine retinal pericytes, the application of methylglyoxal induced apoptosis via increases in ROS levels (6); however, the potential molecular mechanisms underlying increased ROS production in the pathogenesis of DR remain unclear. Mitochondria are the major source of superoxide production and are subject to direct attack by ROS (7). In diabetes, the dysfunction of retinal mitochondria has been reported, and overexpression of mitochondrial superoxide dismutase was observed to protect retinal and vascular cells against high glucose (HG)-induced increases in oxidative stress and DNA damage (8). Additionally, it was reported that hypoxic and hyperglycemic conditions increased the levels of NADPH oxidase (Nox) 2 and Nox 4 isoforms, which led to the overproduction of ROS (9). These findings suggest that increased Nox activity may serve a critical role in the development of DR.

Notch signaling, an evolutionarily conserved pathway, has been demonstrated to serve pivotal roles in retinal development and vascular homeostasis $(10,11)$. Notch signaling involves five ligands, including $\delta$-like 1, 3, 4; Jagged 1, 2 and four receptors, including Notch-1, 2, 3, 4 and the transcription factor, recombination signal-binding protein $\mathrm{J}$ (RBPj). Upon activation, Notch intracellular domain (NICD) is released and translocates to the nucleus where NICD binds RBPj (12). The resulting complex contributes to the regulation of the expression of downstream target genes (13). In diabetic mice and HG-treated human retinal vascular endothelial cells, it was reported that reduced expression levels of Notch1 were associated with the induction of apoptosis (14). The present study aimed to investigate the role and association of Notch signaling and Nox4-associated ROS in HG-induced injury of human retinal endothelial cells (HRECs). The results indicated that Nox4 expression levels were significantly increased in HG-treated HRECs, and that Nox4-mediated ROS may serve a key role in HG-induced HREC death. In addition, the present study proposed that Notch1 signaling activation mediated increases in Nox4 expression. Therefore, the inhibition of Notch signaling or Nox4 expression may be considered as potential therapeutic targets in patients with DR.

\section{Materials and methods}

Cell culture and treatment. HRECs (ACBRI 181; Cell Systems, Kirkland, WA, USA) were cultured at $37^{\circ} \mathrm{C}$ in $5 \%$ $\mathrm{CO}_{2}$ incubator in a fibronectin-coated plate with Dulbecco's modified Eagle's medium (cat. no. 11885-084) supplemented with $10 \%$ fetal calf serum (cat. no. 16000-044) and $100 \mathrm{U} / \mathrm{ml}$ of penicillin/streptomycin (cat. no. 15140-122), all obtained from Gibco (Thermo Fisher Scientific, Inc., Waltham, MA USA). HRECs of passages 3-6 were used for analysis in the present study. Cells were cultured for the indicated durations
$(0,6,12$, and $24 \mathrm{~h})$ in the presence of $30 \mathrm{mM}$ glucose $(\mathrm{HG}$; cat. no. G8270; Sigma-Aldrich, Merck KGaA, Darmstadt, Germany) or osmotic control mannitol (MN; cat. no. PHR1007; Sigma-Aldrich; Merck KGaA). In addition, cells were treated with $50 \mu \mathrm{M} \gamma$-secretase inhibitor IX (GSI; cat. no. 565770; Merck KGaA), $5 \mu \mathrm{M}$ diphenyleneiodonium chloride (DPI; cat. no. D2926; Sigma-Aldrich; Merck KGaA), or $5 \mu \mathrm{M}$ GKT137831 (cat. no. 17764; Cayman Chemical Company, Ann Arbor, MI, USA) at $37^{\circ} \mathrm{C}$ for $24 \mathrm{~h}$, which were added to the medium alone or in appropriate combinations (HG plus DPI, GKT or GSI).

Overexpression of NICD. In the present study, overexpression of NICD was generated by transfection of pCAGGS-NICD (a gift from Professor Nicholas Gaiano, cat. no. 26891, Addgene, Inc., Cambridge, MA, USA) using Lipofectamine ${ }^{\circledR} 2000$ (cat. no. 11668-027; Invitrogen; Thermo Fisher Scientific, Inc.) according to the manufacturer's protocols. Transfection with a blank vector pCAGGS (a gift from Professor Phil Sharp; cat. no. 41583; Addgene, Inc.) was used as the control. Briefly, cells were grown in 6-well plate and transfected with pCAGGS-NICD or blank vector pCAGGS using Lipofectamine $2000(2.5 \mu \mathrm{g}$ plasmid DNA and $5.0 \mu \mathrm{l}$ Lipofectamine 2000 per well) when at $80 \%$ confluence. A total of $6 \mathrm{~h}$ following transfection, medium was changed and cells were cultured for $24 \mathrm{~h}$ in the absence or presence of HG.

Cell death detection. Apoptotic cell death was determined by detection of cytoplasmic histone-associated DNA fragments using the Cell Death Detection ELISA kit (cat. no. 11774 425 001; Roche Diagnostics GmbH, Mannheim, Germany) according to the manufacturer's protocols. Experiments were conducted in triplicate in each condition as described above. The absorbance at 405 and $490 \mathrm{~nm}$ (reference wavelength) was determined with a microplate reader (Bio-Tec Instruments, Inc., Winooski, VT, USA). Signals of the wells containing the substrate alone were used as the background and the experimental values obtained from analysis were subtracted.

Caspase 3 activity detection. The levels of activated caspase-3 were measured using the Caspase-3 Colorimetric Protease Assay kit (cat. no. KHZ0022; Invitrogen; Thermo Fisher Scientific, Inc.) according to the manufacturer's protocols. The fold change relative to the control was presented.

Knockdown assay. To downregulate the expression levels of Nox4 and RBPj, small interfering (si)RNA-Nox4 (siNox4; sc-41586; Santa Cruz Biotechnology, Inc., Dallas, TX, USA) and siRNA-RBPj (sc-38214; Santa Cruz Biotechnology, Inc.) were transfected (final concentrations, 10 and $20 \mathrm{nM}$ ) into cells with RNAiMAX (cat. no. 13778-075; Invitrogen; Thermo Fisher Scientific, Inc.), respectively. Cells were then collected after $72 \mathrm{~h}$ following transfection. Non-targeted siRNA (siCTL; sc-37007, Santa Cruz Biotechnology, Inc.) and nontransfected cells were used as the control.

Reverse transcription-quantitative polymerase chain reaction $(R T-q P C R)$. Total RNA was extracted from nontreated and HG or MN alone as well as HG plus siRNA treated cells using an RNeasy Mini kit (cat. no. 74106; Qiagen GmbH, 
Table I. Primer sequences employed for reverse transcription-quantitative polymerase chain reaction.

\begin{tabular}{lll}
\hline Gene & \multicolumn{1}{c}{ Forward primer } & \multicolumn{1}{c}{ Reverse primer } \\
\hline Nox1 & 5'-CCACTGTAGGCGCCCTAAGTT-3' & 5'-ATGACCGGTGCAAGGATCC-3' \\
Nox2 & 5'-GCCCAAAGGTGTCCAAGCT-3' & 5'-TCCCCAACGATGCGGATAT-3' \\
Nox3 & 5'-CCTTCTGTAGAGACCGCTATGCA-3' & 5'-GACCACAGGGCCTAAAATCCA-3' \\
Nox4 & 5'-GACTTTACAGGTATATCCGGAGCAA-3' & 5'-TGCAGATACACTGGGACAATGTAGA-3' \\
Nox5 & 5'-CAGGCACCAGAAAAGAAAGCAT-3' & 5'-TGTTGATCCAGATAAAGTCCACCTT-3' \\
Notch1 & 5'-CAATGTGGATGCCGCAGT TGTG-3' & 5'-CAGCACCTTGGCGGTCTCGTA-3' \\
Notch2 & 5'-AAAAATGGGGCCAACCGAGAC-3' & 5'-TTCATCCAGAAGGCGCACAA-3' \\
Notch3 & 5'-AGATTCTCATCCGAAACCGCTCTA-3' & 5'-GGGGTCTCCTCCTTGCTATCCTGTG-3' \\
RBPj & 5'-GCTGACTTATGCATTGCCTCAGGA-3' & 5'-CCACTGCTGTGAACTGGCATGAAA-3' \\
GAPDH & 5'-TGTGTCCGTCGTGGATCTGA-3' & 5'-CCTGCTTCACCACCTTCTTGA-3'
\end{tabular}

Nox, NADPH oxidase; RBPj, recombination signal-binding protein $\mathrm{J}$.

Hilden, Germany) and the concentration was determined with an ND-1000 spectrophotometer (NanoDrop Technologies; Thermo Fisher Scientific, Inc., Wilmington, DE, USA). A total of three independent experiments were performed. A total of $2 \mu \mathrm{g}$ RNA was reverse transcribed into cDNA for use with the SuperScript ${ }^{\mathrm{TM}}$ III First-Strand Synthesis kit (cat. no. 11752-050; Thermo Fisher Scientific, Inc.) according to the manufacturer's protocols. qPCR was then performed using a 7500 fast Real-Time PCR system (Applied Biosystems; Thermo Fisher Scientific, Inc.). The SYBR Green PCR Master Mix (cat. no. 1725270; Bio-Rad Laboratories, Inc., Hercules, CA, USA) was used, in which $1.5 \mu \mathrm{l} \mathrm{cDNA}$ and $0.2 \mu \mathrm{M}$ of specific primer pairs (Table I) were included. A two-step PCR program was performed: Initial denaturation at $95^{\circ} \mathrm{C}$ for $10 \mathrm{~min}$; 40 cycles of $95^{\circ} \mathrm{C}$ for $15 \mathrm{sec}$ and $60^{\circ} \mathrm{C}$ for $45 \mathrm{sec}$. The mRNA expression levels of Nox1-5 and Notch1-3 as well as $\mathrm{RBPj}$ were normalized to the housekeeping gene GAPDH. The relative expression levels of the target genes were calculated using the $2^{-\Delta \Delta \mathrm{Cq}}$ method (15). The fold-change relative to the control was presented in the present study.

ROS detection. In nontreated and $\mathrm{HG}$ or $\mathrm{MN}$ alone as well as HG plus DPI or GKT treated cells, the levels of cellular ROS were measured using a DCFDA Cellular ROS Detection Assay kit (cat. no. ab113851; Abcam, Cambridge, MA, USA) according to the manufacturer's protocols; the fold change relative to the controls was compared.

Western blotting. Total cellular protein was extracted using radioimmunoprecipitation assay buffer $(20 \mathrm{mM}$ Tris- $\mathrm{HCl}$ pH 7.5, $150 \mathrm{mM} \mathrm{NaCl}, 1 \mathrm{mM}$ EGTA, 1\% NP-40, $1 \%$ SDS, $2.5 \mathrm{mM}$ sodium pyrophosphate, $1 \mathrm{mM} \beta$-glycerophosphate, $1 \mathrm{mM} \mathrm{Na} \mathrm{VO}_{4}, 1 \mu \mathrm{g} / \mathrm{ml}$ leupeptin and $1 \mathrm{mM}$ PMSF). Nuclear protein was isolated using the Nuclear Extraction kit (ab113474; Abcam). A total of three independent experiments were performed. Protein concentration was quantified using a Pierce $^{\mathrm{TM}}$ bicinchoninic acid Protein Assay kit (cat. no. 23225; Thermo Fisher Scientific, Inc.). A total of $50 \mu \mathrm{g}$ protein was separated using 7.5 or $12.5 \%$ SDS-PAGE, and then transferred to a nitrocellulose membrane (Abcam). The membrane was blocked at room temperature for $1 \mathrm{~h}$ in $5 \%$ low-fat milk prepared in Tris-buffered saline containing $0.1 \%$ Tween-20 (TBST), and then incubated for overnight at $4^{\circ} \mathrm{C}$ with the following primary antibodies: Rabbit anti-B-cell lymphoma 2 (Bcl-2; 1:500; cat. no. ab32124; Abcam), mouse anti-Bcl-2-associated X (Bax; 1:1,000; cat. no. ab77566; Abcam), rabbit anti-Nox4 (1:200; cat. no. ABC459; Merck KGaA), mouse anti-histone H3 (1:11,000; cat. no. 14269S; Cell Signaling Technology, Inc., Danvers, MA, USA), rabbit anti-RBPj (1:500; cat. no. SAB1410700; Sigma-Aldrich; Merck KGaA), rabbit anti-Notch1 (1:400; cat. no. 3608S; Cell Signaling Technology, Inc.), rabbit anti-Notch 1 Antibody N-terminus (1:500; cat. no. 07-1232; Merck KGaA), and mouse anti- $\beta$-actin (1: 10,000; cat. no. A2228; Sigma-Aldrich; Merck KGaA). Histone H3 and $\beta$-actin was used as an internal reference for the expression level of nuclear protein and total cellular protein, respectively. Following five washes with TBST, the membranes were incubated with horseradish peroxidase-conjugated goat anti-rabbit or goat anti-mouse IgG antibodies (1:5,000; cat. nos. G-21234 and G-21040; Invitrogen; Thermo Fisher Scientific, Inc.) for $1 \mathrm{~h}$ at room temperature. Following five washes with TBST, the blots were developed using an Enhanced Chemiluminescence Western Blotting Substrate (cat. no. 32109; Pierce; Thermo Fisher Scientific, Inc.), and the intensity of the bands was quantified using Image J software (version 1.51s; National Institute of Health, Bethesda, MD, USA).

Statistical analysis. A total of three independent experiments were performed in the present study. Data are presented as the mean \pm standard deviation. One-way analysis of variance with the Turkey's post-hoc test was used to conduct statistical analysis (GraphPad Prism 6.0, GraphPad Software, Inc., La Jolla, CA, USA). $\mathrm{P}<0.05$ was considered to indicate a statistically significant difference.

\section{Results}

Increased ROS production is associated with HG-induced cell death in HRECs. It has been well reported that oxidative stress serves a key role in the induction of cellular 

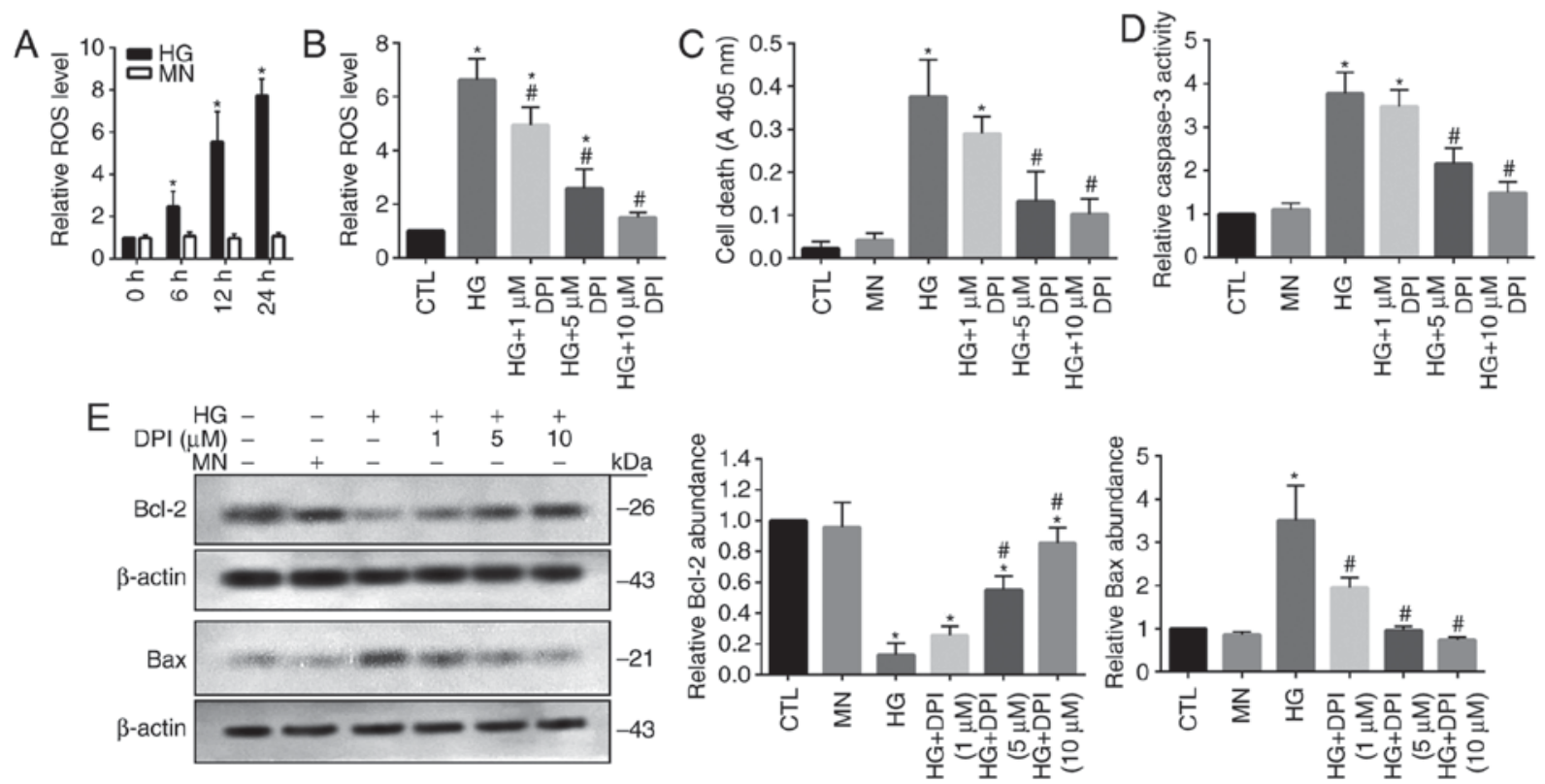

Figure 1. Increased ROS is associated with HG-induced cell death in human retinal endothelial cells. (A) Cells were cultured in the presence of HG or MN, and the ROS levels was evaluated. (B) Cells were cultured for $24 \mathrm{~h}$ in the presence of HG and treated with DPI. Cells cultured in standard glucose media were used as the CTL. The ROS levels were then evaluated. Cells were cultured for $24 \mathrm{~h}$ in the presence of HG or MN, and treated with DPI. (C) Cell death, (D) caspase 3 activity, and (E) protein expression levels of $\mathrm{Bcl}-2$ and Bax were evaluated. Data are presented as the mean \pm standard deviation. $\mathrm{n}=3$. ${ }^{*} \mathrm{P}<0.05$ vs. 0 h, CTL or MN, ${ }^{\#} \mathrm{P}<0.05$ vs. HG. Bcl-2, B-cell lymphoma 2; Bax, Bcl-2-associated X; CTL, control; DPI, diphenyleneiodonium; HG, high-glucose; MN, mannitol; ROS, reactive oxygen species.

apoptosis (16). Thus, the present study investigated the levels of ROS in HG-treated HRECs; MN-treated cells were used as the osmotic controls. A significant time-dependent increase in cellular ROS levels was detected in HG-treated cells compared with in cells at $0 \mathrm{~h}$ and the MN group (Fig. 1A). To reveal the role of ROS overproduction in HG-treated HRECs, the generation of ROS was inhibited by the administration of DPI. Treatment with DPI has been applied to eliminate the production of ROS mediated by flavoenzymes, particularly by Nox (17). The results of the present study demonstrated that HG-mediated increases in ROS levels were significantly inhibited by DPI treatment in a dose-dependent manner compared with in the control and HG groups; however, $10 \mu \mathrm{M}$ DPI did not notably affect ROS production compared with in the control (Fig. 1B). As previously reported, increased apoptotic cell death was detected in HG-treated HRECs (18), which may be associated with the DPI-mediated depletion of ROS; however, 5 and $10 \mu \mathrm{M}$ DPI exhibited a significant effect on cell apoptosis compared with in the $\mathrm{MN}$ and control groups (Fig. 1C). Caspase 3, a critical cellular apoptosis-inducing protease (19), demonstrated significantly elevated activity levels within HG-treated cells compared with in the MN and control groups, which was inhibited by DPI in dose-dependent manner; however 5 and $10 \mu \mathrm{M}$ DPI did not significantly affect caspase 3 activity compared with in the MN and control groups (Fig. 1D). Consistently, the results from western blot analysis revealed significant reductions in the expression levels of cellular survival protein, Bcl-2 and upregulation of proapoptotic protein Bax in HG-treated cells compared with in the MN and control groups, which was inhibited by the addition of DPI (Fig. 1E). These data suggested that activation of oxidative stress signaling-associated proteins may serve a role in HG-induced HREC injury.
Nox4 upregulation is associated with HG-induced HRECs injury. NADPH oxidase generates superoxide by transferring electrons from NADPH within the cell across the membrane and is coupled to molecular oxygen to produce a superoxide anion, a major source of ROS (9). In the present study, the mRNA expression levels of various isoforms of Nox were investigated, including Nox1, 2, 3, 4 and 5 within HG-treated HRECs. RT-qPCR demonstrated that only Nox4 mRNA expression levels were significantly increased at $24 \mathrm{~h}$ in HG-treated cells compared with in the $\mathrm{MN}$ and control groups (Fig. 2A). Furthermore, a time-dependent increase in Nox 4 mRNA and protein abundance was observed in HG-treated cells; however, the expression levels at 24 and $48 \mathrm{~h}$ were significantly elevated compared with $0 \mathrm{~h}$ (Fig. 2B and C). To investigate whether Nox4 serves a major role in the induction of ROS and cellular death within HG-treated HRECs, Nox4 activity was inhibited by using GKT137831. The results revealed that treatment with GKT137831 significantly inhibited ROS levels and cell death, as well as the activity of caspase 3 compared with in the HG group (Fig. 3A-C). To specifically reveal the role of Nox4, knockdown of Nox4 expression was conducted by using siNox4. The results revealed that siNox4 (10 and $20 \mu \mathrm{M}$ ) significantly reduced the protein and mRNA expression levels of Nox4 compared with in the control groups (Fig. 3D and E). As expected, depletion of Nox4 expression significantly decreased apoptotic cell death and caspase 3 activity in HG-treated cells compared with in the control group (Fig. 3F and G). These findings indicated that Nox4-mediated oxidative stress may serve an important role in $\mathrm{HG}$-induced HREC injury.

Notchl signaling is involved in HG-induced cell death in HRECs. Notch signaling pathway is highly conserved and 

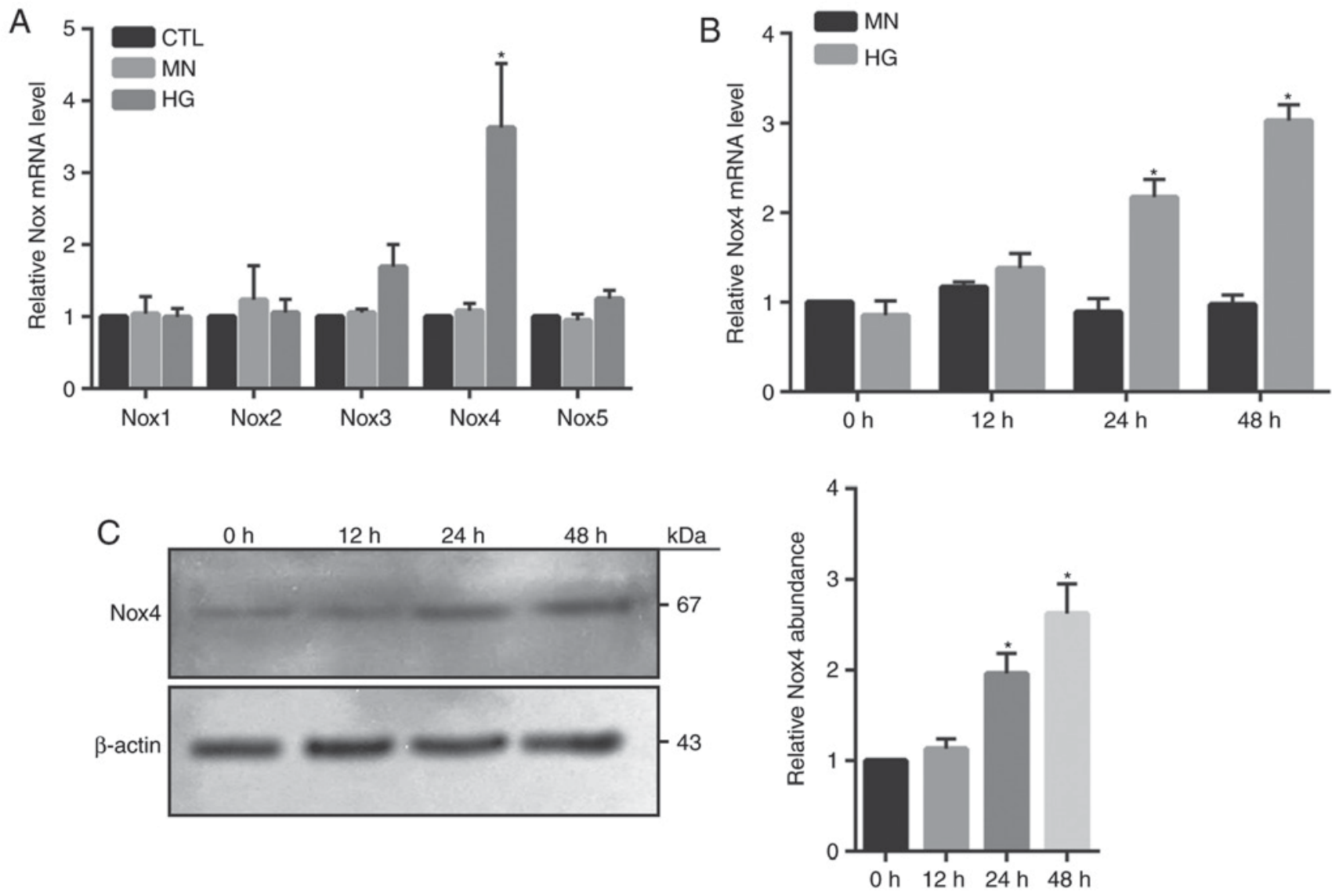

Figure 2. Nox4 is increased in HG-treated human retinal endothelial cells. (A) Cells were cultured for $24 \mathrm{~h}$ in the presence of: Standard glucose as the CTL, HG or MN. The mRNA expression levels of Nox 1-5 were quantitatively evaluated. (B) Cells were cultured for different durations in the presence of HG or MN; the mRNA expression levels of Nox4 was quantitated. (C) Cells were cultured for different durations in the presence of HG, and the protein expression levels of Nox4 were evaluated via an immunoblot assay. Data are presented as the mean \pm standard deviation. $\mathrm{n}=3$. ${ }^{\mathrm{P}}<0.05 \mathrm{vs}$. CTL, MN or $0 \mathrm{~h}$. CTL, control; HG, high-glucose; MN, mannitol; Nox, NADPH oxidase.

involves numerous different Notch receptors (12). It was reported that Notch signaling serves a crucial role in the regulation of apoptotic cell death (20). Compared with in the control groups, Notch1 mRNA expression levels were significantly increased in HG-treated cells as determined by RT-qPCR; however, Notch2 and Notch3 exhibited no notable alterations in expression (Fig. 4A). Western blotting demonstrated a significant time-dependent increase in the abundance of NICD and reductions in total Notch1 following HG treatment compared with $0 \mathrm{~h}$ treatment (Fig. 4B). Additionally, significantly increased NICD expression levels were also detected in the isolated nuclear fractions from HG-treated cells at 24 and $48 \mathrm{~h}$ compared with $0 \mathrm{~h}$ (Fig. 4C), indicating that NICD may act as a transcriptional factor.

To investigate the function of the Notch signaling pathway, in HG-treated HRECs, Notch activity was suppressed via the administration of GSI, which inhibits the cleavage of Notch and therefore NICD production. Western blotting revealed that the expression levels of Notch1 were significantly increased in GSI-treated cells compared with in the control, while that of NICD were significantly reduced (Fig. 5A). HG-induced apoptosis was also significantly inhibited in response to treatment with GSI (Fig. 5B). In addition, NICD was successfully overexpressed in HRECs following transfection with pCAGGS-NICD (Fig. 5C); apoptosis was significantly increased in cells overexpressing NICD compared with in the control groups (Fig. 5D). Consistently, HG-induced cell death was significantly enhanced by NICD overexpression compared with the HG groups and the control (Fig. 5E). These findings indicated that overactivation of the Notch signaling pathway may be associated with HG-mediated HREC injury.

Inhibition of Notch signaling suppresses Nox4 upregulation in HG-treated HRECs. To determine the potential association between Notch1 and Nox4, the effects of Notch signaling on Nox4 expression were investigated in the present study. HG-induced increases in Nox4 mRNA and protein expression were significantly inhibited via the application of GSI compared with the HG group (Fig. 6A and B), suggesting that the Notch signaling pathway may be required for the induction of Nox4 in HG-treated HRECs. Following Notch activation, NICD is produced by the cleavage of $\gamma$-secretase and is then translocated to nucleus, in which nuclear NICD associates with $\mathrm{RBPj}$, leading to regulation of target gene expression (21). In the present study, $\mathrm{RBPj}$ expression was significantly reduced via siRNA-RBPj (10 and $20 \mu \mathrm{M})$ compared with in the control groups (Fig. 6C and D). Knockdown of RBPj significantly decreased Nox4 expression levels within HG-treated cells compared with in the HG groups (Fig. 6E). These data demonstrated that HG may enhance Nox4 expression potentially by 

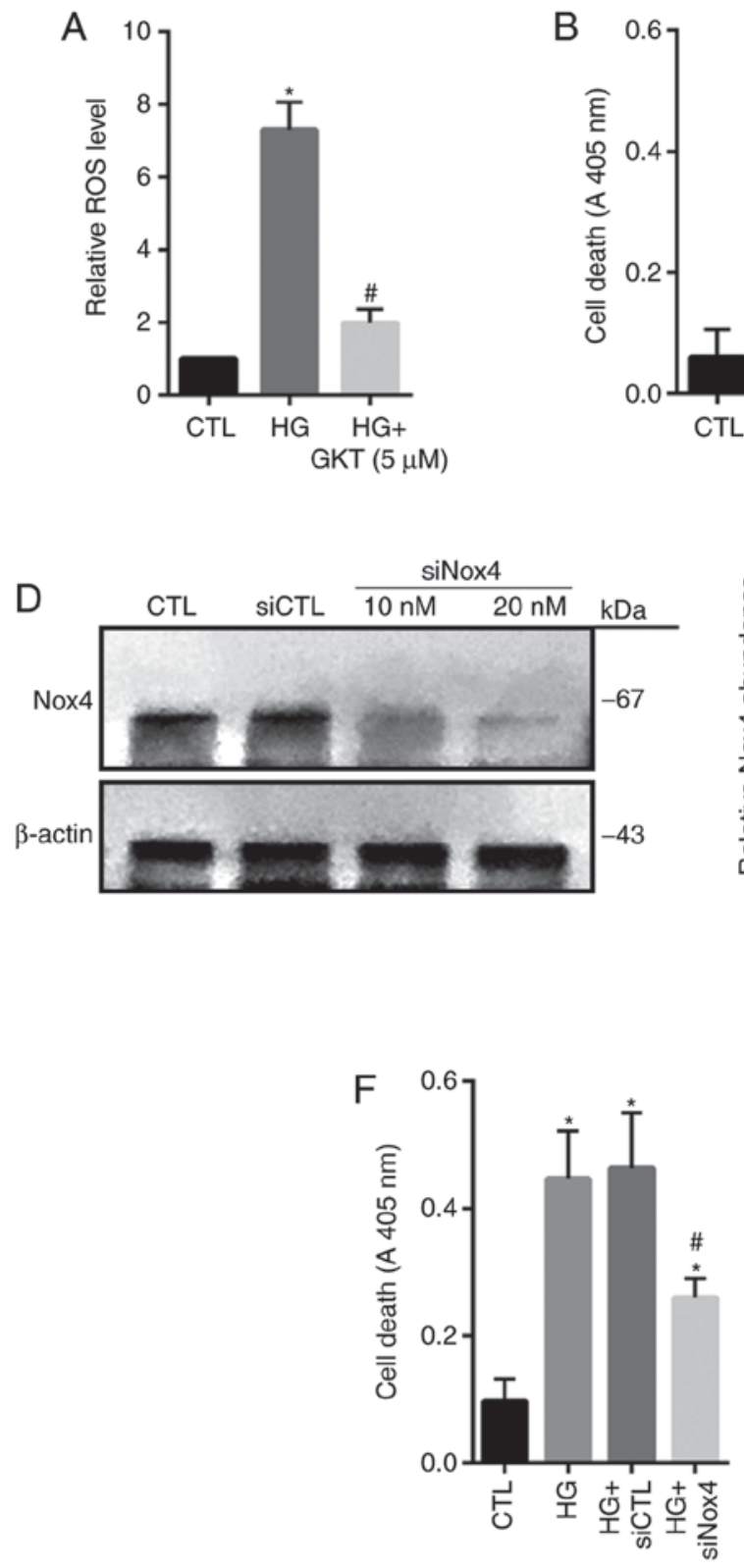
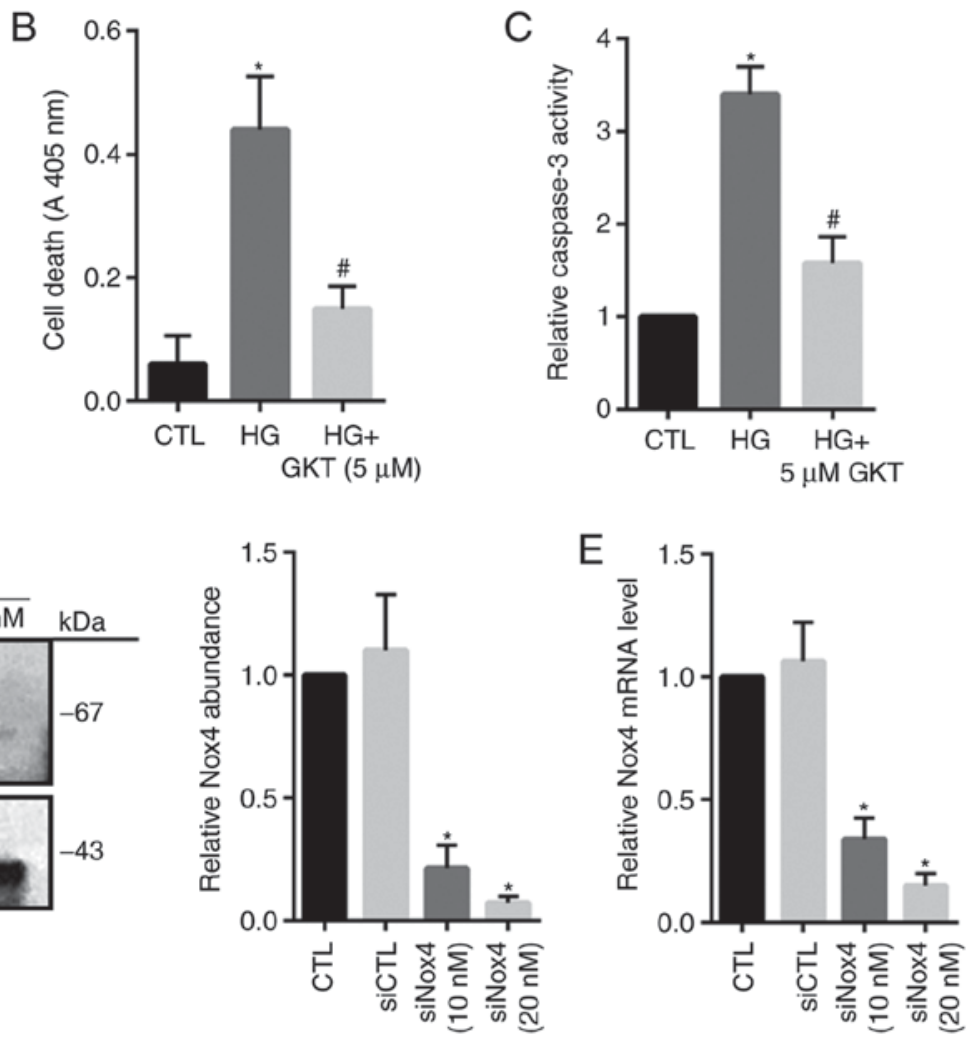

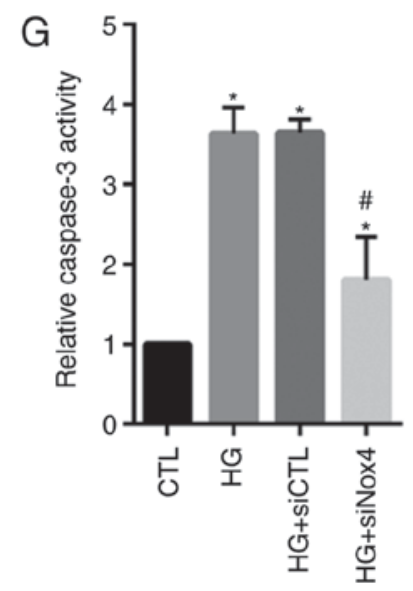

Figure 3. Inhibition of Nox4 suppresses HG-induced cell death in human retinal endothelial cells. Cells were cultured for $24 \mathrm{~h}$ in the presence of: Standard glucose as the CTL, HG, or HG and GKT $(5 \mu \mathrm{M})$. (A) ROS level, (B) cell death and (C) caspase 3 activity were assessed, respectively. Cells were cultured and transfected with siCTL $(20 \mathrm{nM}$ ) or siNox4 (10 or $20 \mathrm{nM})$. (D) Protein and (E) mRNA expression levels of Nox4 were measured via an immunoblot assay and reverse transcription-quantitative polymerase chain reaction. Cells were cultured for $24 \mathrm{~h}$ in the presence of HG and treated with $20 \mathrm{nM}$ of siNox 4 or siCTL. (F) Cell death and (G) caspase 3 activity were assessed, respectively. Data are presented as the mean \pm standard deviation. $n=3$. "P $<0.05$ vs. CTL or siCTL, ${ }^{\#} \mathrm{P}<0.05$ vs. HG or HG + siCTL. CTL, control; Nox4, NADPH oxidase 4; GKT, GKT137831, Nox4 inhibitor; HG, high-glucose; siRNA, small interfering RNA; siCTL, control siRNA; siNox4, Nox4 siRNA.

increasing Notch activity. Over all, the results of the present study suggest that under the conditions of HG, nuclear NICD is produced and then induces upregulation of Nox4 expression, thus increasing ROS level and cell death (Fig. 6F).

\section{Discussion}

In the present study, a novel signaling pathway underlying increased ROS production and retinal vascular cell death was investigated under $\mathrm{HG}$ conditions. The findings of the present study demonstrated that activation of the Notch signaling pathway may promote Nox4 expression, which in turn lead to increased ROS production and cell death in HG-treated HRECs.

In patients with diabetes, increased oxidative stress has been recognized as a major cause of retinal inflammation (22). Providing that the retina requires high levels of oxygen (22), the retina and its vasculature may be susceptible to oxidative stress. It has been reported that oxidative stress and ROS serve critical roles in the pathogenesis of DR (23-25). Excessive ROS can cause endothelial dysfunction and apoptosis, leading to the loss of vascular cells (26). In the present study, exposure to 

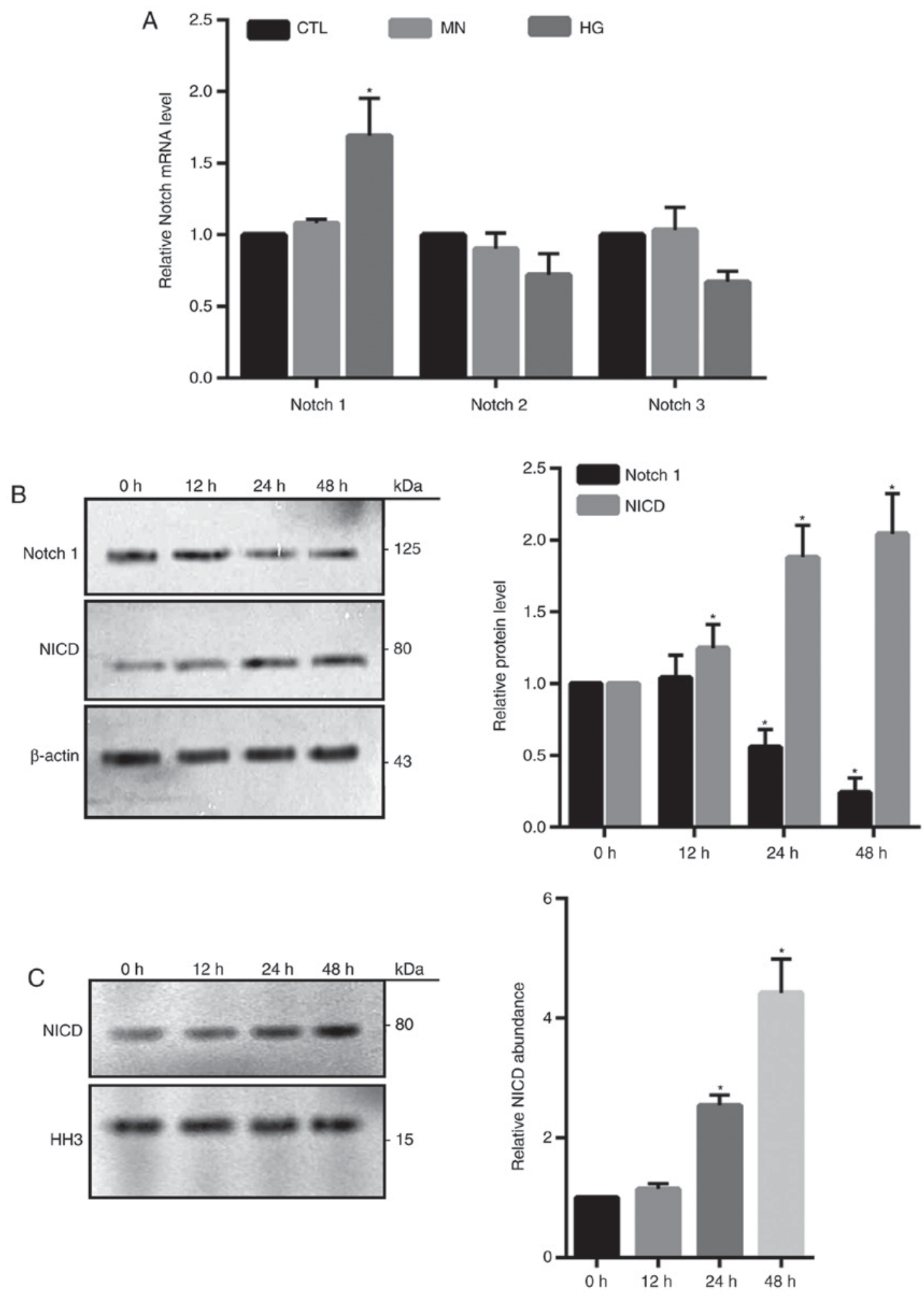

Figure 4. Notch signaling is activated in HG-treated human retinal endothelial cells. (A) Cells were cultured for $24 \mathrm{~h}$ in the presence of: Standard glucose as the CTL, HG or MN. The mRNA expression levels of Notch1-3 were quantified. Cells were cultured for different durations in the presence of HG. (B) Expression levels of total Notch1 and NICD were evaluated via an immunoblot assay. (C) Nuclear fraction was isolated and the abundance of NICD was evaluated via an immunoblot assay. Data are presented as the mean \pm standard deviation. $n=3 .{ }^{*} \mathrm{P}<0.05$ vs. CTL, MN or 0 h. CTL, control; HG, high-glucose; HH3, histone H3; MN, mannitol; NICD, Notch1 intracellular domain.

HG significantly increased the apoptosis of cultured HRECs. Following the addition of $\mathrm{HG}$, a time-dependent increase in intracellular ROS levels was also detected, whereas depletion of ROS production by the administration of DPI significantly decreased HG-induced cell death. In HG-treated cells, increased caspase 3 activity and the proapoptotic Bax protein expression levels were decreased in response to DPI. These findings suggested that enhanced oxidative stress serves an important role in HG-induced HRECs injury, and that the use of specific antioxidant may be a potential therapeutic target to 

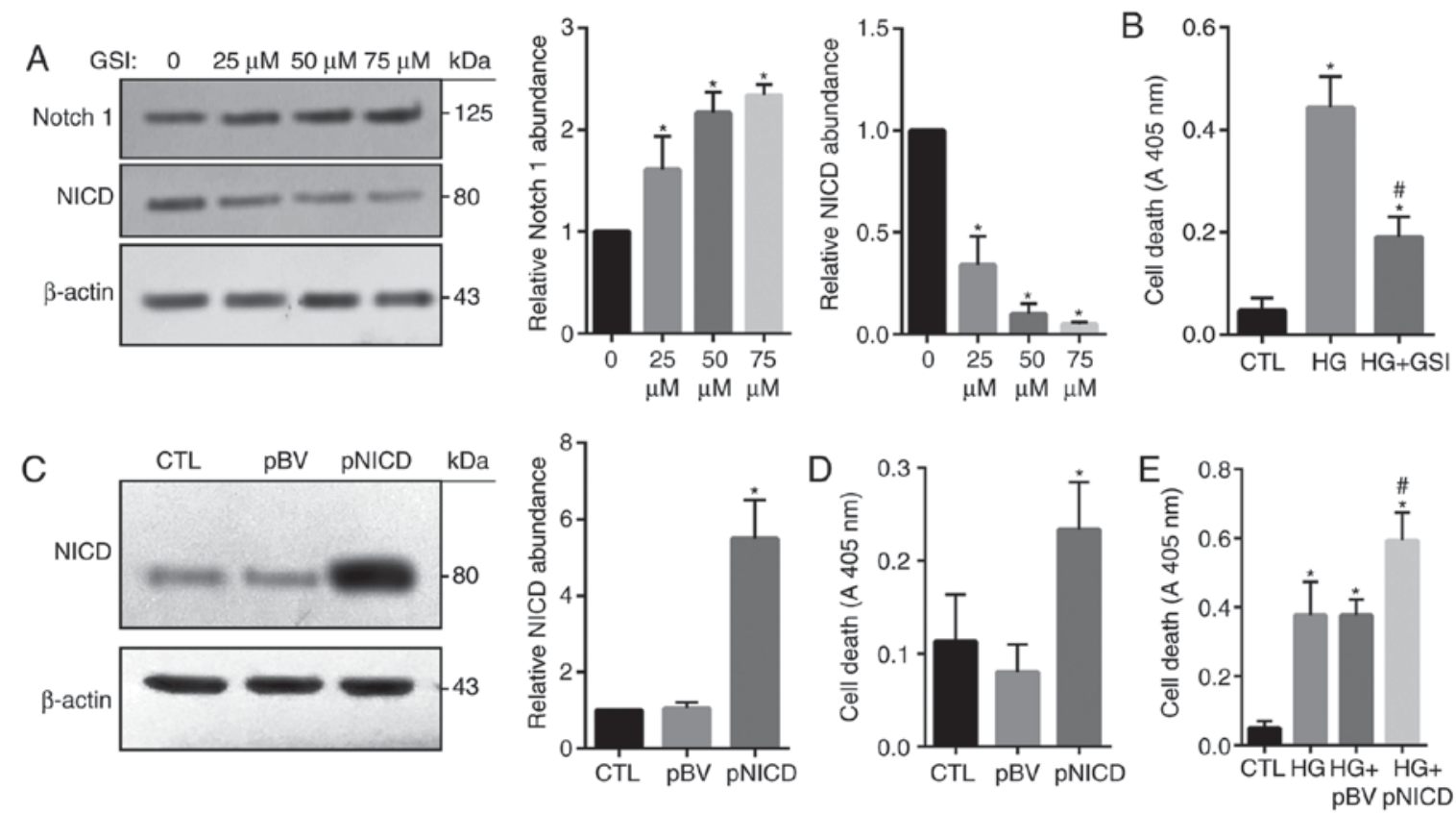

Figure 5. Notch1 signaling is involved in HG-induced cell death in human retinal endothelial cells. (A) Cells were cultured and treated with GSI to inhibit Notch signaling. The expression levels of NICD and Notch1 were evaluated via immunoblotting. (B) Cells were cultured for $24 \mathrm{~h}$ in the presence of: Standard glucose as the CTL, HG, or HG and GSI $(50 \mu \mathrm{M})$. Cell death was assessed. (C) Cells were transfected with pBV or the pNICD. Overexpressed NICD was detected via an immunoblot assay; (D) the effect of NICD on cell death was assessed. (E) Cells were cultured for $24 \mathrm{~h}$ in the presence of $\mathrm{HG}$ and $\mathrm{pBV}$ or pNICD. Cell death was then evaluated. Data are presented as the mean \pm standard deviation. $\mathrm{n}=3$. ${ }^{*} \mathrm{P}<0.05$ vs. $0 \mu \mathrm{M}, \mathrm{CTL}$ or $\mathrm{pBV},{ }^{\sharp} \mathrm{P}<0.05 \mathrm{vs}$. $\mathrm{HG}$ or $\mathrm{HG}+\mathrm{pBV}$. CTL, control; GSI, $\gamma$-secretase inhibitor; HG, high-glucose; NICD, Notch1 intracellular domain; pBV, black vector; pNICD, overexpressing NICD vector

obtain optimal levels of ROS in DR. A major source of ROS is the NADPH oxidase system in endothelial cells $(27,28)$. NADPH oxidase mainly comprises five isoforms, Nox1-5 (29). The results of RT-qPCR in the present study revealed that Nox4 mRNA expression levels had increased significantly, whereas that of Nox1, 2, and 3 exhibited no notable change within HG-treated HRECs; however, within cultured bovine retinal endothelial cells (BRECs) stimulated with $20 \mathrm{mM} \mathrm{HG}$, upregulated Nox 2 mRNA expression levels and activity were reported (30). In the retinal microvasculature isolated from the retina of patients with DR, the expression of Nox 2 was also increased (30). Additionally, it was reported that Nox2 protein expression levels were increased in retinas isolated from rats with DR, and that inhibition of Nox 2 mediated by simvastatin may be associated with normalization of ROS levels and reductions in retinal vascular injury (31). In the present study, $30 \mathrm{mM} \mathrm{HG}$ was applied to cultured HRECs, which increased the expression of Nox4 at the mRNA and protein levels; however, Nox 2 expression levels did not exhibit significant alterations. Various concentrations of $\mathrm{HG}$ and cellular types may explain these controversial results. Of note, Nox4 expression levels were not investigated in HG-treated BRECs, and the retina of patients or rats with DR. In addition, as a limitation of the present study, in vivo investigations were not conducted. The varying expression levels of Nox isoforms require further investigation in animal models of DR. Previous studies have also reported that Nox4 is a major isoform of NADPH oxidase in retinal microvascular endothelial cells $(32,33)$. To investigate the role of Nox4 in HG-treated HRECs, a Nox4 inhibitor GKT137831 and an siRNA designed to target human Nox4 were employed in the present study. Inhibition of Nox4 prevented HG-induced increases in ROS production in HRECs. The induction of caspase 3 activity and apoptosis was also prevented by Nox 4 inhibition and knockdown. Therefore, enhanced Nox4 expression may serve a critical role in HG-induced HREC apoptosis, and Nox4 may be considered as a therapeutic target to ameliorate vascular injury in DR. In addition, regarding the activation of Nox proteins, numerous signaling pathways have been identified to be associated with the progression of DR, including the activation of protein kinase $\mathrm{C}$, the formation of advanced glycation end products, the peroxynitrite, hexosamine and polyol signaling pathways (9).

In the present study, the mechanisms by which $\mathrm{HG}$ induces the upregulation of Nox4 in HRECs were investigated. In renal tubular epithelial cells, Nox4 was reported to be involved HG-induced cell death via Notch signaling (34). Additionally, within primary human umbilical vein endothelial cells, inhibition of Notch signaling led to increases in intracellular ROS via Nox4 upregulation (35). These findings suggest a potential association between Nox4 and Notch signaling. The Notch signaling pathway is a highly conserved cell signaling system that is present in the majority of multicellular organisms (36). In mammals, there are four different Notch receptors, referred to as Notch1, Notch2, Notch3 and Notch4. In the angiogenic process, alternative and distinct roles for different Notch ligands have been identified in the retina (37). The present study reported that Notch1 mRNA expression levels were significantly increased in HG-treated HRECs, whereas Notch2 and Notch3 exhibited no notable change. The abundance of NICD was observed to increase in a time-dependent manner in whole cellular lysates and in the nuclear fractions from HG-treated cells. Notch is a transmembrane protein; NICD is produced from the cleavage of Notch by $\gamma$-secretase $(37,38)$. 
A

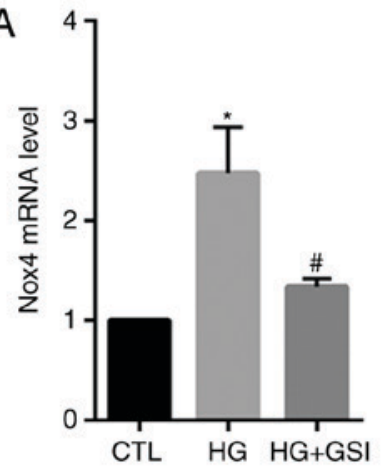

C

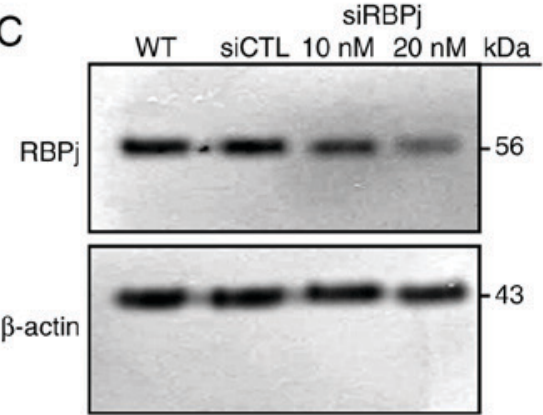

B

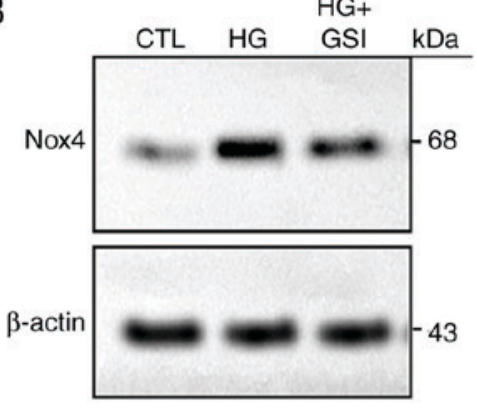

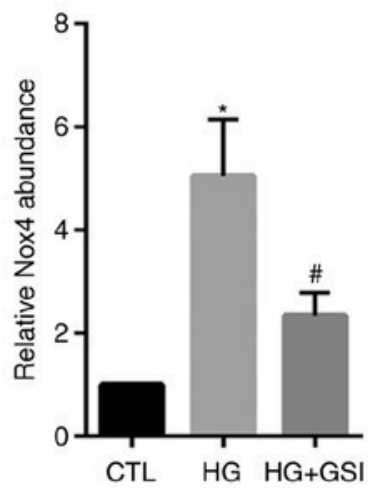

D

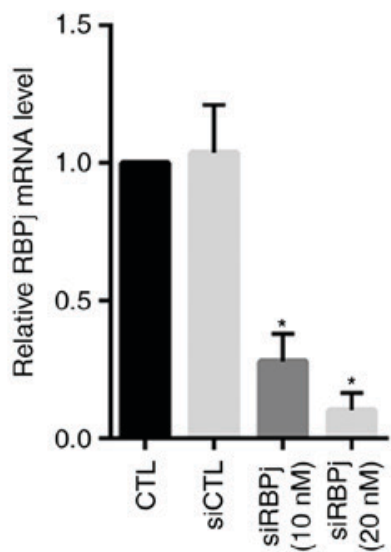

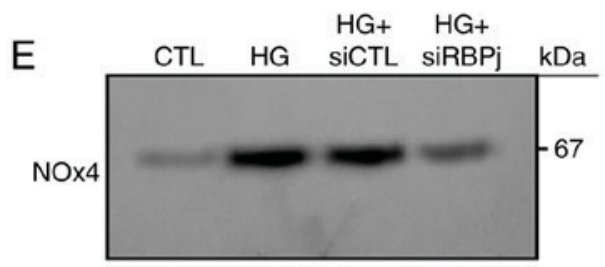
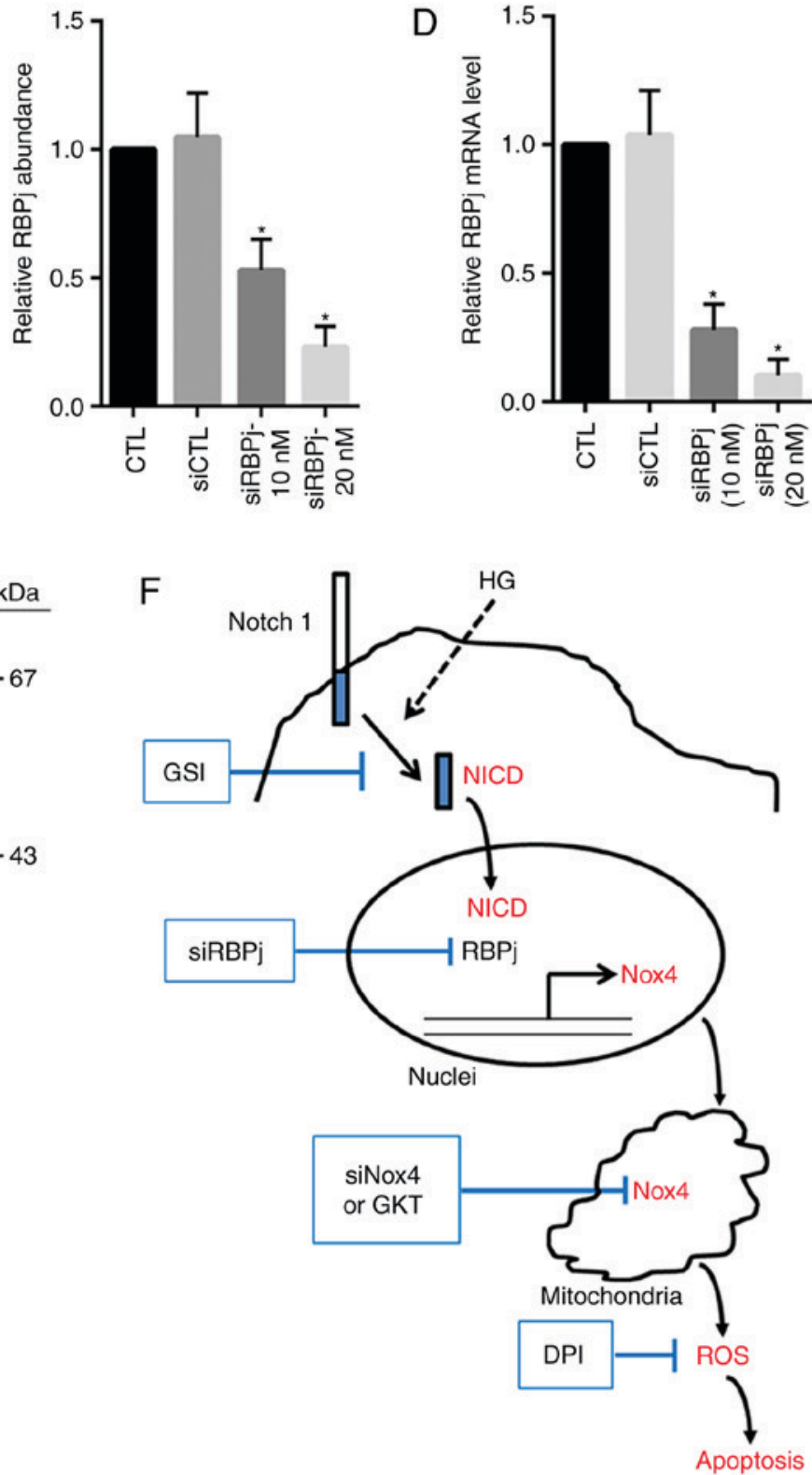

Figure 6. Inhibition of Notch signaling suppresses Nox4 expression in HRECs. Cells were cultured for $24 \mathrm{~h}$ in the presence of: Standard glucose as the CTL, HG, or HG and GSI (50 $\mu \mathrm{M})$. The expression of Nox4 at the (A) mRNA and (B) protein levels was evaluated. Cells were cultured and transfected with siCTL or siRBPj (10 or $20 \mathrm{nM}$ ). (C) Protein and (D) mRNA expression levels of RBPj were measured via immunoblotting and reverse transcription-quantitative polymerase chain reaction, respectively. (E) Cells were cultured for $24 \mathrm{~h}$ in presence of HG alone, or HG and $20 \mathrm{nM}$ siRBPj. Nox4 protein expression levels were evaluated. Data are presented as the mean \pm standard deviation. $n=3$. ${ }^{*} \mathrm{P}<0.05$ vs. CTL or siCTL, ${ }^{\text { }} \mathrm{P}<0.05$ vs. HG or HG+siCTL. (F) Schematic of the role of the Notch-Nox4-ROS signaling pathway in HG-induced HRECs injury. Under the conditions of HG, NICD is expressed and is then translocated to the nucleus; NICD induces the upregulation of Nox4 via complex formation of NICD and RBPj. Increased Nox4 upregulates ROS production that is responsible for the induction of cell death. CTL, control; GSI, $\gamma$-secretase inhibitor; HG, high-glucose; HRECs, human retinal endothelial cells; NICD, Notch1 intracellular domain; RBPj, recombination signal-binding protein J; Nox4, NADPH oxidase 4; ROS, reactive oxygen species; siRNA, small interfering RNA; siCTL, control-siRNA; siRBPj, RBPj-siRNA. 
The released NICD then enters the cell nucleus to regulate the expression of specific genes associated with the control of cell fate (38).

In retinal pigment epithelium cells, Notch2 was demonstrated to be the major Notch receptor, and inhibition of Notch2 markedly attenuated intracellular ROS production and cellular apoptosis in ultraviolet B-induced damage (39). To reveal the role of Notch signaling in HG-induced HRECs apoptosis or cell death, GSI was used to prevent the cleavage of Notch and NICD production in the present study. GSI was observed to significantly decrease NICD abundance and HG-induced cell death. Apoptosis was significantly increased in HG-treated HRECs overexpressing NICD. The results of the present study suggested that the activation of the Notch signaling pathway serves a pivotal role in HG-mediated HRECs injury. In retinal ganglion cells, hypoxia-induced Notch1 expression and signaling activation, and inhibition of Notch signaling significantly aggravated hypoxia-induced cell apoptosis (40). In a co-culture system of ligand-dependent Notch activation using primary cultured retinal pericytes and a mesenchymal cell line derived from an inducible mouse model expressing $\delta$-like 1 Notch ligand, ligand-mediated Notch activity was observed to protect retinal pericytes from light-induced cell death (41). It has been reported that Notch signaling is highly pleiotropic and can affect differentiation, proliferation and/or apoptotic events in numerous ways that depend on their integration with other signaling pathways (42). The present study investigated the effects of inhibiting Notch activity on Nox4 expression levels in HG-treated HRECs. The results study revealed that treatment with GSI significantly suppressed HG-induced upregulation of Nox4 at mRNA and protein levels, suggesting that HG may enhance Nox4 expression via the activation of the Notch signaling pathway in HRECs. To further confirm the role of Notch activation in HG-induced Nox4 expression, the expression of RBPj was downregulated with a specific siRNA. $\mathrm{RBPj}$ is a co-activator that can promote gene expression by associating with Notch (43). The constitutive activation of Notch enhanced retinal pigment epithelium cell proliferation, which was dependent on the presence of the transcription factor RBPj (44). In the present study, knockdown of RBPj prevented HG-induced increases in the expression levels of Nox4.

Collectively, the results of the present study demonstrated that HG upregulates Nox4 expression via the activation of Notch signaling, resulting in increased ROS production and cell death in HRECs. Inhibition of Notch signaling or Nox4 expression may be potential therapeutic strategies for the treatment of DR. However, to further confirm the role of the Notch-Nox4-ROS signaling pathway in the pathogenesis of DR, future investigations with primary cultured HRECs, or conditional Notch or Nox4 knockout mice may be conducted.

\section{Acknowledgements}

Not applicable.

\section{Funding}

The present study was supported by the Natural Science Foundation of China (grant no. 61572300, 81871508 and
61773246), the Taishan Scholar Program of Shandong Province (grant no. TSHW201502038), and the Key Research and Development Program of Shandong Province (grant no. 2017GSF18178).

\section{Availability of data and materials}

Not applicable.

\section{Authors' contributions}

WJ, JJ and WX conceived designed the experiments. WJ performed the experiments. WJ, WX, FL and JG analyzed the data. WJ, YZ and SL performed the statistical analysis. WJ wrote and submitted the manuscript. WJ and JJ and WX revised the manuscript. All authors reviewed and approved the final manuscript.

\section{Ethics approval and consent to participate}

Not applicable.

\section{Patient consent to publication}

Not applicable.

\section{Competing interests}

The authors declare that they have no competing interests.

\section{References}

1. Yau JW, Rogers SL, Kawasaki R, Lamoureux EL, Kowalski JW, Bek T, Chen SJ, Dekker JM, Fletcher A, Grauslund J, et al: Global prevalence and major risk factors of diabetic retinopathy. Diabetes Care 35: 556-564, 2012.

2. Kanwar M, Chan PS, Kern TS and Kowluru RA: Oxidative damage in the retinal mitochondria of diabetic mice: Possible protection by superoxide dismutase. Invest Ophthalmol Vis Sci 48: 3805-3811, 2007.

3. Adamiec-Mroczek J, Oficjalska-Młyńczak J and Misiuk-Hojło M: Roles of endothelin-1 and selected proinflammatory cytokines in the pathogenesis of proliferative diabetic retinopathy: Analysis of vitreous samples. Cytokine 49: 269-274, 2010.

4. Behl Y, Krothapalli P, Desta T, DiPiazza A, Roy S and Graves DT: Diabetes-enhanced tumor necrosis factor-alpha production promotes apoptosis and the loss of retinal microvascular cells in type 1 and type 2 models of diabetic retinopathy. Am J Pathol 172: 1411-1418, 2008.

5. Kowluru RA, Tang J and Kern TS: Abnormalities of retinal metabolism in diabetes and experimental galactosemia. VII. Effect of long-term administration of antioxidants on the development of retinopathy. Diabetes 50: 1938-1942, 2001.

6. Kim J, Son JW, Lee JA, Oh YS and Shinn SH: Methylglyoxal induces apoptosis mediated by reactive oxygen species in bovine retinal pericytes. J Korean Med Sci 19: 95-100, 2004.

7. Saccà SC, Cutolo CA, Ferrari D, Corazza P and Traverso CE: The eye, oxidative damage and polyunsaturated fatty acids. Nutrients 10: pii: E668, 2018.

8. Kowluru RA, Atasi L and Ho YS: Role of mitochondrial superoxide dismutase in the development of diabetic retinopathy. Invest Ophthalmol Vis Sci 47: 1594-1599, 2006.

9. Coucha M, Elshaer SL, Eldahshan WS, Mysona BA and El-Remessy AB: Molecular mechanisms of diabetic retinopathy: Potential therapeutic targets. Middle East Afr J Ophthalmol 22: 135-144, 2015.

10. Hatakeyama $\mathbf{J}$ and Kageyama R: Retinal cell fate determination and bHLH factors. Semin Cell Dev Biol 15: 83-89, 2004. 
11. Hellström M, Phng LK, Hofmann JJ, Wallgard E, Coultas L, Lindblom P, Alva J, Nilsson AK, Karlsson L, Gaiano N, et al: Dll4 signalling through Notch1 regulates formation of tip cells during angiogenesis. Nature 445: 776-780, 2007.

12. Borggrefe $\mathrm{T}$ and Oswald $\mathrm{F}$ : The Notch signaling pathway: Transcriptional regulation at Notch target genes. Cell Mol Life Sci 66: 1631-1646, 2009.

13. Zheng M, Zhang Z, Zhao X, Ding Y and Han H: The Notch signaling pathway in retinal dysplasia and retina vascular homeostasis. J Genet Genomics 37: 573-582, 2010.

14. Qin X, Zhang Z, Xu H and Wu Y: Notch signaling protects retina from nuclear factor- $\mathrm{kB}$ - and poly-ADP-ribose-polymerase-mediated apoptosis under high-glucose stimulation. Acta Biochim Biophys Sin (Shanghai) 43: 703-711, 2011.

15. Livak KJ and Schmittgen TD: Analysis of relative gene expression data using real-time quantitative PCR and the 2(-Delta Delta C(T)) method. Methods 25: 402-408, 2001.

16. Dehdashtian E, Mehrzadi S, Yousefi B, Hosseinzadeh A Reiter RJ, Safa M, Ghaznavi H and Naseripour M: Diabetic retinopathy pathogenesis and the ameliorating effects of melatonin; involvement of autophagy, inflammation and oxidative stress. Life Sci 193: 20-33, 2018 .

17. Lee JE, Cho KE, Lee KE, Kim J and Bae YS: Nox4-mediated cell signaling regulates differentiation and survival of neural crest stem cells. Mol Cells 37: 907-911, 2014

18. El-Remessy AB, Rajesh M, Mukhopadhyay P, Horváth B Patel V, Al-Gayyar MM, Pillai BA and Pacher P: Cannabinoid 1 receptor activation contributes to vascular inflammation and cell death in a mouse model of diabetic retinopathy and a human retinal cell line. Diabetologia 54: 1567-1578, 2011.

19. Shalini S, Dorstyn L, Dawar S and Kumar S: Old, new and emerging functions of caspases. Cell Death Differ 22: 526-539, 2015.

20. Tian DY, Jin XR, Zeng X and Wang Y: Notch signaling in endothelial cells: Is it the therapeutic target for vascular neointimal hyperplasia? Int J Mol Sci 18: pii: E1615, 2017.

21. Tanigaki $\mathrm{K}$ and Honjo T: Two opposing roles of RBP-J in Notch signaling. Curr Top Dev Biol 92: 231-252, 2010.

22. Zhang W, Liu H, Al-Shabrawey M, Caldwell RW and Caldwell RB: Inflammation and diabetic retinal microvascular complications. J Cardiovasc Dis Res 2: 96-103, 2011.

23. Tarr JM, Kaul K, Chopra M, Kohner EM and Chibber R: Pathophysiology of diabetic retinopathy. ISRN Ophthalmol 2013: 343560, 2013.

24. Caldwell RB, Bartoli M, Behzadian MA, El-Remessy AE, Al-Shabrawey M, Platt DH, Liou GI and Caldwell RW: Vascular endothelial growth factor and diabetic retinopathy: Role of oxidative stress. Curr Drug Targets 6: 511-524, 2005.

25. Ali TK and El-Remessy AB: Diabetic retinopathy: Current management and experimental therapeutic targets. Pharmacotherapy 29: 182-192, 2009.

26. Radak D, Resanovic I and Isenovic ER: Link between oxidative stress and acute brain ischemia. Angiology 65: 667-676, 2014.

27. Babior BM: The NADPH oxidase of endothelial cells. IUBMB Life 50: 267-269, 2000

28. Frey RS, Ushio-Fukai $M$ and Malik AB: NADPH oxidase-dependent signaling in endothelial cells: Role in physiology and pathophysiology. Antioxid Redox Signal 11: 791-810, 2009 .
29. Wingler K, Hermans JJ, Schiffers P, Moens A, Paul M and Schmidt HH: NOX1, 2, 4, 5: Counting out oxidative stress. Br J Pharmacol 164: 866-883, 2011.

30. Kowluru RA, Kowluru A, Veluthakal R, Mohammad G, Syed I, Santos JM and Mishra M: TIAM1-RAC1 signalling axis-mediated activation of NADPH oxidase-2 initiates mitochondrial damage in the development of diabetic retinopathy. Diabetologia 57: 1047-1056, 2014.

31. Al-Shabrawey M,Bartoli M,El-Remessy AB, Ma G, Matragoon S, Lemtalsi T, Caldwell RW and Caldwell RB: Role of NADPH oxidase and Stat 3 in statin-mediated protection against diabetic retinopathy. Invest Ophthalmol Vis Sci 49: 3231-3238, 2008.

32. Li J, Wang JJ and Zhang SX: NADPH oxidase 4-derived $\mathrm{H} 2 \mathrm{O} 2$ promotes aberrant retinal neovascularization via activation of VEGF receptor 2 pathway in oxygen-induced retinopathy. J Diabetes Res 2015: 963289, 2015.

33. Wang H, Yang Z, Jiang Y and Hartnett ME: Endothelial NADPH oxidase 4 mediates vascular endothelial growth factor receptor 2-induced intravitreal neovascularization in a rat model of retinopathy of prematurity. Mol Vis 20: 231-241, 2014.

34. Yao M, Gao F, Wang X, Shi Y, Liu S and Duan H: Nox4 is involved in high glucose-induced apoptosis in renal tubular epithelial cells via Notch pathway. Mol Med Rep 15: 4319-4325, 2017.

35. Cai WX, Liang L, Wang L, Han JT, Zhu XX, Han H, Hu DH and Zhang P: Inhibition of Notch signaling leads to increased intracellular ROS by up-regulating Nox4 expression in primary HUVECs. Cell Immunol 287: 129-135, 2014.

36. Artavanis-Tsakonas S, Rand MD and Lake RJ: Notch signaling: Cell fate control and signal integration in development. Science 284: 770-776, 1999.

37. Hofmann JJ and Luisa Iruela-Arispe M: Notch expression patterns in the retina: An eye on receptor-ligand distribution during angiogenesis. Gene Expr Patterns 7: 461-470, 2007.

38. Oswald F, Täuber B, Dobner T, Bourteele S, Kostezka U, Adler G, Liptay S and Schmid RM: p300 acts as a transcriptional coactivator for mammalian Notch-1. Mol Cell Biol 21: 7761-7774, 2001.

39. Liu L, Zhou X, Kuang X, Long C, Liu W, Tang Y, Liu H, He J, Huang Z, Fan Y, Zhang Q and Shen H: The inhibition of NOTCH2 reduces UVB-induced damage in retinal pigment epithelium cells. Mol Med Rep 16: 730-736, 2017.

40. Li H, Zhu Z, Liu J, Wang J and Qu C: MicroRNA-137 regulates hypoxia-induced retinal ganglion cell apoptosis through Notch1. Int J Mol Med 41: 1774-1782, 2018

41. Arboleda-Velasquez JF, Primo V, Graham M and James A, Manent J and D'Amore PA: Notch signaling functions in retinal pericyte survival. Invest Ophthalmol Vis Sci 55: 5191-5199, 2014.

42. Hori K, Sen A and Artavanis-Tsakonas S: Notch signaling at a glance. J Cell Sci 126: 2135-2140, 2013

43. Wang H, Zang C, Taing L, Arnett KL, Wong YJ, Pear WS Blacklow SC, Liu XS and Aster JC: NOTCH1-RBPJ complexes drive target gene expression through dynamic interactions with superenhancers. Proc Natl Acad Sci USA 111: 705-710, 2014

44. Schouwey K, Aydin IT, Radtke F and Beermann F: RBP-JK-dependent Notch signaling enhances retinal pigment epithelial cell proliferation in transgenic mice. Oncogene 30: 313-322, 2011. 